\title{
Functional Movement Screen for Predicting Running Injuries in 18- to 24-Year-Old Competitive Male Runners.
}

\section{$\operatorname{AUTHOR}(\mathrm{S}):$}

Hotta, Takayuki; Nishiguchi, Shu; Fukutani, Naoto; Tashiro, Yuto; Adachi, Daiki; Morino, Saori; Shirooka, Hidehiko; ... Hirata, Hinako; Yamaguchi, Moe; Aoyama, Tomoki

\section{CITATION:}

Hotta, Takayuki ...[et al]. Functional Movement Screen for Predicting Running Injuries in 18- to 24-Year-Old Competitive Male Runners.. Journal of strength and conditioning research 2015, 29(10): 2808-2815

\section{ISSUE DATE:}

2015-10

URL:

http://hdl.handle.net/2433/202830

\section{RIGHT:}

(c) 2015 by the National Strength \& Conditioning Association; This is a non-final version of an article published in final form in [Journal of Strength \& Conditioning Research: October 2015, Volume 29, Issue 10, p 2808-2815, doi:

10.1519/JSC.0000000000000962]; The full-text file will be made open to the public on 1 October 2016 in accordance with publisher's 'Terms and Conditions for Self-Archiving'.; This is not the published version. Please cite only the published version.; この論文は出版社版でありません。引用の際には出版社版をご確認ご利用ください。 
FMS and running injury 1

1 Functional Movement Screen for Predicting Running Injuries in 18-24 Year-Old Competitive

2 Male Runners 
FMS and running injury 2

\section{ABSTRACT}

The purpose of this study was to investigate whether the functional movement screen (FMS) could predict running injuries in competitive runners. Eighty-four competitive male runners (average age $=20.0 \pm 1.1$ years) participated. Each subject performed the FMS, which consisted of 7 movement tests (each score range: $0-3$, total score range: $0-21$ ), during the pre-season. The incidence of running injuries (time lost due to injury $\leq 4$ weeks) was investigated through a follow-up survey during the 6-month season. Mann-Whitney U tests were used to investigate which movement tests were significantly associated with running injuries. The receiver-operator characteristic (ROC) analysis was used to determine the cut-off. The mean FMS composite score was $14.1 \pm 2.3$. The ROC analysis determined the cut-off at $14 / 15$ (sensitivity $=0.73$, specificity $=0.54$ ), suggesting that the composite score had a low predictability for running injuries. However, the total score (0-6) from the deep squat (DS) and active straight leg raise (ASLR) tests (DS \& ASLR), which were significant with the $U$ test, had relatively high predictability at the cut-off of $3 / 4$ (sensitivity $=0.73$, specificity $=0.74)$. Furthermore, the multivariate logistic regression analysis revealed that the DS \& ASLR scores of $\leq 3$ significantly influenced the incidence of running injuries after adjusting for subjects' characteristics (OR $=9.7$, 95\%CI [2.1 to 44.4]). Thus, the current study identified the DS \& ASLR score as a more effective method than the composite score to screen the risk of running injuries in competitive male runners.

KEY WORDS: Distance runner, Screening, Dynamic assessment, Risk factor 
FMS and running injury 3

\section{INTRODUCTION}

The functional movement screen (FMS) is a screening tool for injury risk that assesses the movement patterns of individuals, and which can evaluate mobility and stability comprehensively. The FMS consists of 7 component tests, each scored based on the movement patterns within the kinetic chain, asymmetries between the sides, and compensatory movements. The validity of the FMS as a predictor of injury risk has been confirmed in several studies $(6,11,12,18)$. The first, by Kiesel et al. (11), examined the relationship between the FMS and serious injury in professional football players. They revealed that professional football players with an FMS score of $\leq 14$ were at a greater risk of serious injury than those with higher scores (11). Other studies reported similar findings in other groups, such as officer candidates $(12,18)$ and female collegiate athletes (6).

Recently, two studies investigated normative values of FMS scores for runners. Loudon et al (13) reported the normative value for running athletes and Agresta et al. (1) reported it for healthy runners (the mean FMS composite scores were $13.1 \pm 1.8$ and $15.4 \pm$ 2.4, respectively). Additionally, Agresta et al. investigated the association between FMS scores and injury history. However, no prospective cohort studies have investigated the association between the FMS and running injuries. Running injuries are a serious problem for most runners, especially for competitive runners (9). Unfortunately, some runners are forced to retire from running due to serious running injuries. Previous studies reported some risk factors for running injuries, such as inadequate flexibility (25), muscle weakness and imbalance (17), and deficits in neuromuscular coordination $(20)$. Cook $(7,8)$ stated that these factors also caused poor movement patterns, which were reflected in the lower score of the FMS. Thus, runners with low FMS scores might have certain risk factors for running injury and become more prone to injury. In addition, although Parchmann and McBride (19) reported that the FMS was not significantly associated with sprinting, Chapman (5) revealed 
FMS and running injury 4

that a high FMS score had a positive effect on performance in elite track and field athletes in the long view. Because athletes with a higher FMS score rarely suffered from injury, they could practice continuously and improve their performance. Therefore, we hypothesized that the FMS could predict running injuries.

The receiver-operator characteristic (ROC) curve is a plot of the sensitivity versus 1 - specificity of a screening test; this analysis is useful in determining the cut-off where the sensitivity and specificity are maximized. In previous studies, the ROC curve was used to determine the validity of the FMS as a predictor of injury risk $(3,11,18)$. In addition, a cut-off value allows determining more easily whether a runner has a potential injury risk simply based on the FMS scores. Therefore, the aim of the current study was to determine the cut-off value and to investigate if the FMS score during pre-season could be used to predict running injuries in young competitive runners during season.

\section{METHODS}

\section{Experimental Approach to the Problem}

This study, using a prospective cohort design, investigated whether pre-season FMS scores could predict serious running injuries during the season in 18-24-year-old competitive male runners. Figure 1 illustrates the process of this study in the form of a flow chart. The subjects performed the FMS at their college during pre-season, February 2014. To minimize the influence of fatigue on the performance, the FMS tests were conducted during the daytime on the day following a non-training day according to each team's schedule. No warm-up was included. The testing days added up to 7 days total. After the FMS test, follow-up surveys were distributed to the subjects to investigate the incidence of running injuries during the 6-month season. The follow-up surveys were conducted twice at the end of May and August 2014 to reduce a recall bias. Statistical analyses were conducted using the 
FMS and running injury 5 data of the returned surveys. The ROC analysis determined the cut-off, and the logistic regression analysis determined if the FMS could be used for the prediction of running injuries.

\section{Subjects}

A total of 84 competitive male runners volunteered to participate in the current study (mean age $=20.0 \pm 1.1$ years, age range $=18-24$ years, height $=171.6 \mathrm{~cm} \pm 4.5$, weight $=$ $57.5 \mathrm{~kg} \pm 4.3$ ). For inclusion, subjects had to be competitive male runners belonging to collegiate track and field teams, who were injury-free at the time of the FMS test in pre-season, whose events were middle- or long-distance, and whose running experience exceeded 1 year. The purpose and methods of this study were explained to the subjects in detail in a verbal statement, and written informed consent was obtained from the subjects. The current study did not include athletes under the age of 18 years, thus parental or guardian consent was not needed. This study was approved by the Institutional Review Board of Kyoto University (Approval No. E2023).

\section{Procedures}

Before the study, the physical therapists collecting data in the current study were instructed on the FMS evaluation method by an FMS specialist. The FMS scoring criteria were used as described by Cook et al. $(7,8)$, and they discussed standardization of the testing. On testing day, all subjects were questioned about their characteristics, such as age, height, weight, running experience, training sessions per week, weekly mileage, personal best time in their primary event in 2013, and injury history by questionnaire. To allow comparison between different events, performances were normalized to a percentage of collegiate Japanese record performances (as of March 31, 2013) (5). To assess injury history, we asked 
FMS and running injury 6

98 the following question: "Have you ever suffered from musculoskeletal injury that was so severe that it required medical attention?” (6). Subsequently, all subjects were briefed on the FMS and given a demonstration of the movements. After the demonstration, all subjects performed the FMS, which consisted of 7 movement tests to comprehensively assess mobility, stability, and coordination. The 7 tests were the deep squat (DS), hurdle step (HS), in-line lunge (ILL), shoulder mobility (SM), active straight leg raise (ASLR), trunk stability push-up (TSPU), and rotary stability (RS) tests. All tests were scored using standardized scoring criteria $(7,8)$. Each movement test was scored on a 4-point scale (0-3), and the maximal FMS score that could be achieved was 21. A score of 3 was awarded for perfect form, a score of 2 was given for completing the test with compensations, a score of 1 was awarded for not completing the test accurately, and a score of 0 was given if the subjects felt any pain during the test. Each test was performed 3 times, and the highest score was used. Of the 7 tests that comprise the FMS, 5 tests (HS, ILL, SM, ASLR, and RS) were performed and scored separately for the right and left side of the body. For these bilaterally assessed tests, the lower score was used.

After the FMS test, follow-up surveys were distributed to all subjects through each team's manager to investigate the incidence of running injuries during the 6-month season. If information was missing in the questionnaires, we asked the subjects to answer the omitted questions by contacting them through the team's managers. For the current study, the definition of running injury was a musculoskeletal injury that met the following criteria: (1)

118 the injury occurred as a result of participating in a practice or race in track and field (trauma injuries, such as sprains, were excluded), and (2) the injury was sufficiently severe to prevent participation for at least 4 weeks; this definition was based on that used in previous studies $(11,18)$. 
FMS and running injury 7

123

124

125

126

127

128

129

130

131

132

133

134

135

136

137

138

139

140

141

142

143

144

145

146

147

\section{Reliability}

Similar to a previous study (13), interrater reliability was assessed in a subgroup of 10 subjects by 2 physical therapists. Interrater reliability was calculated for the FMS composite score using the intraclass correlation coefficient (ICC, model 2, 1). On the basis of the reliability coefficients, the standard error of measurement $(S E M=S D \times \sqrt{ } 1$-ICC), the minimum difference to be considered real $(\mathrm{MD}=\mathrm{SEM} \times 1.96 \times \sqrt{2})$, and the standard error of prediction ( $\mathrm{SEP}=\mathrm{SD} \sqrt{1-\mathrm{ICC}^{2}}$ ) were calculated (24). The Bland-Altman analysis was performed to determine whether systematic error was present. The weighed kappa statistic was used to establish the interrater reliability for each movement test of the FMS.

\section{Statistical Analyses}

We divided the subjects into 2 groups with and without running injuries according to the follow-up survey. Comparisons between the 2 groups were made using Student's t-tests (for parametric continuous variables), Mann-Whitney U tests (for non-parametric continuous variables), or chi-squared tests (for categorical variables). The short version of the FMS was calculated from the movement tests that were significant according to the $\mathrm{U}$ tests. The ROC curve was calculated by pairing the FMS score with running injury to determine the cut-off on the FMS that maximized sensitivity and specificity according to previous studies $(3,6,11,18)$. In this context, the FMS can be thought of as a screening test that determines if a runner is at risk for a running injury. An ROC curve is a plot of the sensitivity (true-positive) versus 1 - specificity (false-positive) of a screening test. The area under the curve (AUC) was calculated based on the ROC curve. The optimal cut-off was determined based on the Youden index, which consists of the following formula: Youden index $=($ sensitivity + specificity $)-1$ (2). Maximizing this index allows finding the optimal cut-off value. Once the cut-off value was identified, a $2 \times 2$ contingency table was created dichotomizing those with and without 
FMS and running injury 8

injury, and those above and below the cut-off on the FMS. To determine whether a runner, whose FMS score was below the cut-off, had potential injury risk during season, the multivariate logistic analysis was adjusted for each subject's characteristics including age, height, weight, running experience, training sessions per week, weekly mileage, performance level, and injury history. A value of $p<.05$ was considered to be statistically significant for all analyses. All data were analyzed by using the Statistical Package for the Social Sciences version 20.0 (SPSS, Inc., Chicago, IL).

\section{RESULTS}

In pre-season, 101 runners from 7 teams participated in the FMS. Of the 84 returned the follow-up surveys (response rate was 83.2\%).

\section{Reliability}

Interrater reliability for the FMS composite score is shown in Table 1. ICC $(2,1)$ was 0.98 (95\% confidence interval, CI $[0.93,1.00])$, demonstrating excellent reliability, and the Bland-Altman analysis revealed that there was no systematic error present (both fixed bias and proportional bias). Interrater reliability (weighted kappa) for each component movement test is presented in Table 2 and shows that the majority of the FMS tests demonstrated a substantial to excellent agreement. These results were in accordance with previous studies $(10,16,22)$ and confirmed the reliability of the procedure in the current study.

\section{FMS Score Distribution}

The mean FMS composite score was $14.2 \pm 2.3$ with a range of $7-18$. Of the 84 subjects, $43(51.2 \%)$ scored $\leq 14$ on the FMS composite score, indicating that they had a high injury risk according to Kiesel et al. (11). Among all the subjects, 4 reported pain in the DS 
FMS and running injury 9

and TSPU tests, 3 reported pain in the SM test, 2 reported pain in the ILL test, and 1 reported pain in the HS and RS tests, which resulted in a score of 0 for these tests.

The distribution of scores for each component movement test is presented in Figure

2. The SM test was the movement with the highest frequency of a score of $3(65.5 \%)$. Conversely, the RS was the movement with the highest frequency of a score of 1 (34.5\%); no subject achieved a score of 3 on this test. The DS, HS, ILL, and ASLR tests had the highest frequency of a score of 2 on each test.

\section{FMS Score and Injuries}

Among the 84 subjects, 15 (17.9\%) experienced running injuries during the season. The comparisons between groups with and without running injuries are presented in Table 3. The mean FMS composite scores were $13.3 \pm 2.7$ and $14.4 \pm 2.2$ for subjects with and without any injury, respectively. Although, there was a trend for the injury group to have a lower score, this difference was not significant $(p=.07)$. Of the 7 tests, the scores on the DS and ASLR tests were significant with the $\mathrm{U}$ test. Using the composite score of the 2 tests, we calculated a short version of the FMS, which was named "DS \& ASLR" (score range: 0-6). Figure 3 shows the significant difference in the DS \& ASLR score between the injured and non-injured groups, whose scores were $2.9 \pm 1.0$ and $4.1 \pm 1.1$, respectively $(p<.01)$.

The ROC curves for the FMS composite and DS \& ASLR scores are presented in Figure 4. The cut-off of the FMS composite score was determined to be 14/15, which was consistent with a previous study (11). However, the ROC curve had a relatively low AUC (AUC $=0.65, p=.08$ ), and, at this point, the sensitivity was 0.73 , and the specificity was 0.46 . Subjects were dichotomized into groups with FMS composite scores $\leq 14$ and $\geq 15$, which are presented in Table 4. Conversely, the ROC curve for the DS \& ASLR score had a relatively high AUC (AUC $=0.79, p=.01$ ), and it determined the cut-off to be $3 / 4$ with a sensitivity of 
FMS and running injury 10

198

199

200

201

202

203

204

205

206

207

208

209

210

211

212

213

214

215

216

217

0.73 and a specificity of 0.74 (Figure 4). Subjects were again dichotomized into groups with

DS \& ASLR scores $\leq 3$ and $\geq 4$, which are presented in Table 5 . Among the subjects with a score of $\leq 3$, 11 out of 29 had been injured during the season (injury rate: $37.9 \%$ ), while among the subjects with a score of $\geq 4$, 4 out of 55 (injury rate: 7.3\%) had been injured. The logistic regression analysis revealed similar results presented in Table 6 . A score of $\leq 14$ of the composite FMS did not significantly influence the incidence of running injuries $(\mathrm{OR}=3.0$, 95\%CI $[0.8,11.6], p=.10)$. However, the same analysis revealed that a runner with a DS \& ASLR score of $\leq 3$ was significantly more likely to become injured even when adjusting for each subject's characteristics (OR = 9.7, 95\%CI [2.1, 44.4], $p<.01)$.

\section{DISCUSSION}

The purpose of the current study was to investigate whether the FMS could predict running injuries in competitive male runners. The study revealed that the cut-off on the FMS was $14 / 15$, which was in accordance with a previous study (11), but the composite score of $\leq 14$ had low predictability for running injuries. In contrast, the current study also revealed that a DS \& ASLR score of $\leq 3$ during pre-season was a more useful approach for predicting running injuries during season in 18-24 year-old competitive male runners. This is the first study to investigate the validity of the FMS as a predictor for running injuries and to establish the short version of the FMS (DS \& ASLR) for screening running injuries.

\section{FMS Score Distribution}

The mean FMS composite score for the 18-24-year-old competitive male runners in the current study was $14.1 \pm 2.3$, which is similar to the results of college basketball volleyball, and soccer athletes in Warren et al.’s (23) and Chorba et al.’s (6) studies (mean 
FMS and running injury 11

scores were $14.3 \pm 2.5$ and $14.3 \pm 1.7$, respectively). On the other hand, Loudon et al. (13) reported a mean score for male running athletes of $15.0 \pm 2.4$, while Agresta et al. (1) reported a mean score for healthy male runners of $13.1 \pm 1.7$. Although their findings slightly differ from ours, the runners in the current study had a comparable average performance as other runners. Additionally, our scores were relatively lower than the mean composite scores for professional football players (11) and officer candidates (18) (mean scores were $16.9 \pm$ 3.0 and $16.6 \pm 1.7$, respectively). These differences are expected to occur because distance running mainly requires cardiorespiratory endurance and does not involve as much stability and power as required by football players or candidate officers.

Considering each movement test of the FMS, Figure 2 shows that the subjects performed the best on the SM test, which required mobility of the shoulder and scapula and thoracic spine extension. Since runners need to swing their arms frequently during running, $\mathrm{SM}$ is needed to minimize the burden from arm swing. On the other hand, the subjects performed the worst in the RS test, which requires multi-plane trunk stability during a combined upper and lower extremity motion. This result was similar to results of previous studies $(1,18,21)$; there were only a few subjects who scored 3 on the RS test. Thus, these findings suggest that the RS test may be one of the more difficult tests of the FMS.

\section{FMS Score and Injuries}

The ROC analysis revealed that sensitivity and specificity were 0.73 and 0.74 , respectively. Subsequently, the multivariate logistic regression analysis revealed that subjects with a score of $\leq 3$ on the DS \& ASLR were approximately 10 times more likely to have running injuries than those with a score $\geq 4$ after adjusting for each subject's characteristics. The relatively strong predictability of running injuries according to the DS \& ASLR score was attributed to the following reasons. First, the DS test by itself had a strong predictability 
FMS and running injury 12

of injuries, which was in accordance with the result of Butler et al.'s study (3). The DS test assesses bilateral, symmetrical mobility, especially mobility of hips, ankles, and thoracic spine, and coordination in the close kinetic chain. Renström (20) reported that poor flexibility and deficit in neuromuscular coordination can cause running injuries. Additionally, excessive pronation and knee-in during testing, which was one of the causes that decreased the score on the DS test (7), was also reported to be a risk factor for injury (15). Second, the ASLR test was also found to be related to running injuries; it assesses active hamstring and gastric-soleus flexibility while maintaining a stable pelvis. This finding agreed with the study by Yagi et al. (25), who also reported that limited SLR ability increased the injury risk in high school runners. Additionally, Lysholm et al. (14) reported that flexibility of the hamstrings was a risk factor for injury. Consequently, deficits in the DS and ASLR tests are likely to induce asymmetric or compensatory movement patterns and thus result in running injuries. Thus, the FMS contains both helpful and less helpful movement tests for predicting injury risk in competitive male runners. The HS test assesses stepping ability, which requires mobility and stability of the legs as well as coordination. The ILL test requires mobility and stability in the split stance as well as coordination. Although these 2 tests seem to be relevant for running, they were not significantly associated with incidence of running injury because most subjects received a score of 2 (91.7\% for HS, $86.9 \%$ for ILL). Due to their ceiling effects, these 2 tests were ineffective in screening injury risk. As a result, the FMS composite score had low predictability. For the SM, TSPU, and RS tests, there is no solid evidence that shoulder mobility and core-stability influence the incidence of running injuries.

\section{Limitation}

There were several limitations in the current study. The first is the definition of injury as a running injury (lost training time $\geq 4$ weeks). Although the current study revealed 
FMS and running injury 13

that the DS \& ASLR could predict serious running injuries, it is unclear if it could successfully screen the risk of non-serious running injuries (lost training time $<4$ weeks). A second limitation was the mode of collecting injury data by a self-report questionnaire due to the absence of athletic trainers in all teams. As a result, relevant details, such as type of injury, were not collected. A third limitation was that the current study was carried out among 1824-year-old competitive male runners in Japan. It is unclear whether the results can be extrapolated to other running populations such as female, older, or recreational runners. Therefore, further study is required to ensure the external validity of the DS \& ASLR score for other runners.

\section{PRACTICAL APPLICATIONS}

First, the current study provided reliable normative data for FMS scores among 1824 year-old competitive male runners. These data can be used as reference values for strength and conditioning by professional coaches when they need to assess the injury risk of similar groups using the FMS.

Additionally, the current study revealed that a score of $\geq 4$ or $\leq 3$ of the DS \& ASLR was more useful for predicting running injuries than the FMS composite score in 18-24 year-old competitive male runners. This finding is meaningful for the strength and conditioning professional who supports a similar group of athletes. First, injury risks can be screened easily by using the DS \& ASLR as it only takes approximately 5 minutes. This is an advantage because time is often limited and rather spent on training. Second, it allows the strength and conditioning professional to prevent serious problems in younger runners that could result in retiring from running due to injuries. Timely prediction of injury risks allows initiating strategies for preventing injury. For example, performing hamstring and gastric-soleus stretches are effective in improving scores on the ASLR scores (8). As to the 
FMS and running injury 14

297

298

299

300

301

302

303

304

305

306

307

308

309

310

311

312

313

314

315

316

317

318

319

320

321

DS test, the strength and conditioning professional or physical therapists should assess which deficit is limiting influence on this test before conducting corrective exercises. This is because the DS test is affected by many variables, such as the mobility of the hip, ankle, thoracic spine, and shoulder, the stability of the hip, and coordination (8). The current study suggests that, by improving scores on the DS \& ASLR in pre-season, the incidence of running injuries in 18-24-year-old competitive male runners could be reduced.

\section{References}

1. Agresta, C, Slobodinsky, M, and Tucker, C. Functional Movement ScreenTM - Normative Values in Healthy Distance Runners. Int J Sports Med 35: 1203-1207, 2014.

2. Akobeng, AK. Understanding diagnostic tests 3: Receiver operating characteristic curves. Acta Paediatr 96: 644-647, 2007.

3. Butler, RJ, Contreras, M, Burton, LC, Plisky, PJ, Goode, A, and Kiesel, K. Modifiable risk factors predict injuries in firefighters during training academies. Work 46: 11-17, 2013.

4. Butler, RJ, Plisky, PJ, Southers, C, Scoma, C, and Kiesel, KB. Biomechanical analysis of the different classifications of the Functional Movement Screen deep squat test. Sports Biomech 9: 270-279, 2010.

5. Chapman, RF, Laymon, AS, and Arnold, T. Functional movement scores and longitudinal performance outcomes in elite track and field athletes. Int J Sports Physiol Perform 9: 203211, 2014.

6. Chorba, RS, Chorba, DJ, Bouillon, LE, Overmyer, CA, and Landis JA. Use of a functional movement screening tool to determine injury risk in female collegiate athletes. N Am J Sports Phys Ther 5: 47-54, 2010.

7. Cook, G, Burton, L, and Hoogenboom, B. Pre-participation screening: the use of fundamental movements as an assessment of function - part 1. N Am J Sports Phys Ther 1: 
322

323

324

325

326

327

328

329

330

331

332

333

334

335

336

337

338

339

340

341

342

343

344

345

346

62-72, 2006.

8. Cook, G, Burton, L, and Hoogenboom, B. Pre-participation screening: the use of fundamental movements as an assessment of function - part 2. N Am J Sports Phys Ther 1: 132-139, 2006.

9. Di Caprio, F, Buda, R, Mosca, M, Calabro, A, and Giannini, S. Foot and lower limb diseases in runners: assessment of risk factors. J Sports Sci Med 9: 587-596 2010.

10. Gulgin, H, and Hoogenboom, B. The functional movement screening (FMS): An inter-rater reliability study between raters of varied experience. Int J Sports Phys Ther 9: 1420, 2014.

11. Kiesel, K, Plisky, PJ, and Voight, ML. Can serious injury in professional football be predicted by a preseason functional movement screen? N Am J Sports Phys Ther 2: 147-158, 2007.

12. Lisman, P, O’Connor, FG, Deuster, PA, and Knapik, JJ. Functional movement screen and aerobic fitness predict injuries in military training. Med Sci Sports Exerc 45: 636-643, 2013. 13. Loudon, JK, Parkerson-Mitchell, AJ, Hildebrand, LD, and Teague, C. Functional movement screen scores in a group of running athletes. J Strength Cond Res 28: 909-913 2014.

14. Lysholm, J, and Wiklander, J. Injuries in runners. Am J Sports Med 15: 168-171, 1987. 15. Messier, SP, and Pittala, KA. Etiologic factors associated with selected running injuries. Med Sci Sports Exerc 20: 501-505, 1988.

16. Minick, KI, Kiesel, KB, Burton, L, Taylor, A, Plisky, P, and Butler, RJ. Interrater reliability of the functional movement screen. J Strength Cond Res 24: 479-486, 2010. 17. Niemuth, PE, Johnson, RJ, Myers, MJ, and Thieman, TJ. Hip muscle weakness and overuse injuries in recreational runners. Clin J Sport Med 15: 14-21, 2005.

18. O’Connor, FG, Deuster, PA, Davis, J, Pappas, CG, Knapik, JJ. Functional movement 
FMS and running injury 16

screening: predicting injuries in officer candidates. Med Sci Sports Exerc 43: 2224-2230, 2011.

19. Parchmann, CJ, and McBride, JM. Relationship between functional movement screen and athletic performance. J Strength Cond Res 25: 3378-3384, 2011.

20. Renström, AF. Mechanism, diagnosis, and treatment of running injuries. Instr Course Lect 42: 225-234, 1993.

21. Schneiders, AG, Davidsson, A, Horman, E, and Sullivan, SJ. Functional movement screen normative values in a young, active population. Int J Sports Phys Ther 6: 75-82, 2011.

22. Teyhen, DS, Shaffer, SW, Lorenson, CL, Halfpap, JP, Donofry, DF, Walker, MJ, Dugan, JL, and Childs, JD. The Functional Movement Screen: a reliability study. J Orthop Sports Phys Ther 42: 530-540, 2012.

23. Warren, M, Smith, CA, and Chimera, NJ. Association of Functional Movement Screen With Injuries in Division I Athletes. J Sport Rehabil Sep 8, 2014. Epub ahead of print. 24. Weir, JP. Quantifying test-retest reliability using the intraclass correlation coefficient and the SEM. J Strength Cond Res 19: 231-240, 2005. 25. Yagi, S, Muneta, T, and Sekiya, I. Incidence and risk factors for medial tibial stress syndrome and tibial stress fracture in high school runners. Knee Surg Sports Traumatol Arthrosc 21: 556-563, 2013.

\section{ACKNOWLEDGMENTS}

Special thanks to all the participants who willingly participated in this study. 


\section{LEGENDS}

369 FIGURE 1. Flow chart illustrating the process of the study.

370 FIGURE 2. Distribution of scores for each functional movement screen (FMS) component

371 test.

372 FIGURE 3. Comparison of the DS \& ASLR score between groups with and without injury.

373 FIGURE 4. Receiver-operator characteristic (ROC) curves for FMS composite and DS \& 374 ASLR score.

375 TABLE 1. Interrater reliability for the FMS composite score.

376 TABLE 2. Interrater reliability for each FMS component test.

377 TABLE 3. Comparison of runners with and without running injuries during the season.

378 TABLE $4.2 \times 2$ contingency table: FMS composite score $\times$ running injuries

379 TABLE $5.2 \times 2$ contingency table: DS \& ASLR score $\times$ running injuries.

380 TABLE 6. Influence of the FMS on running injury. 


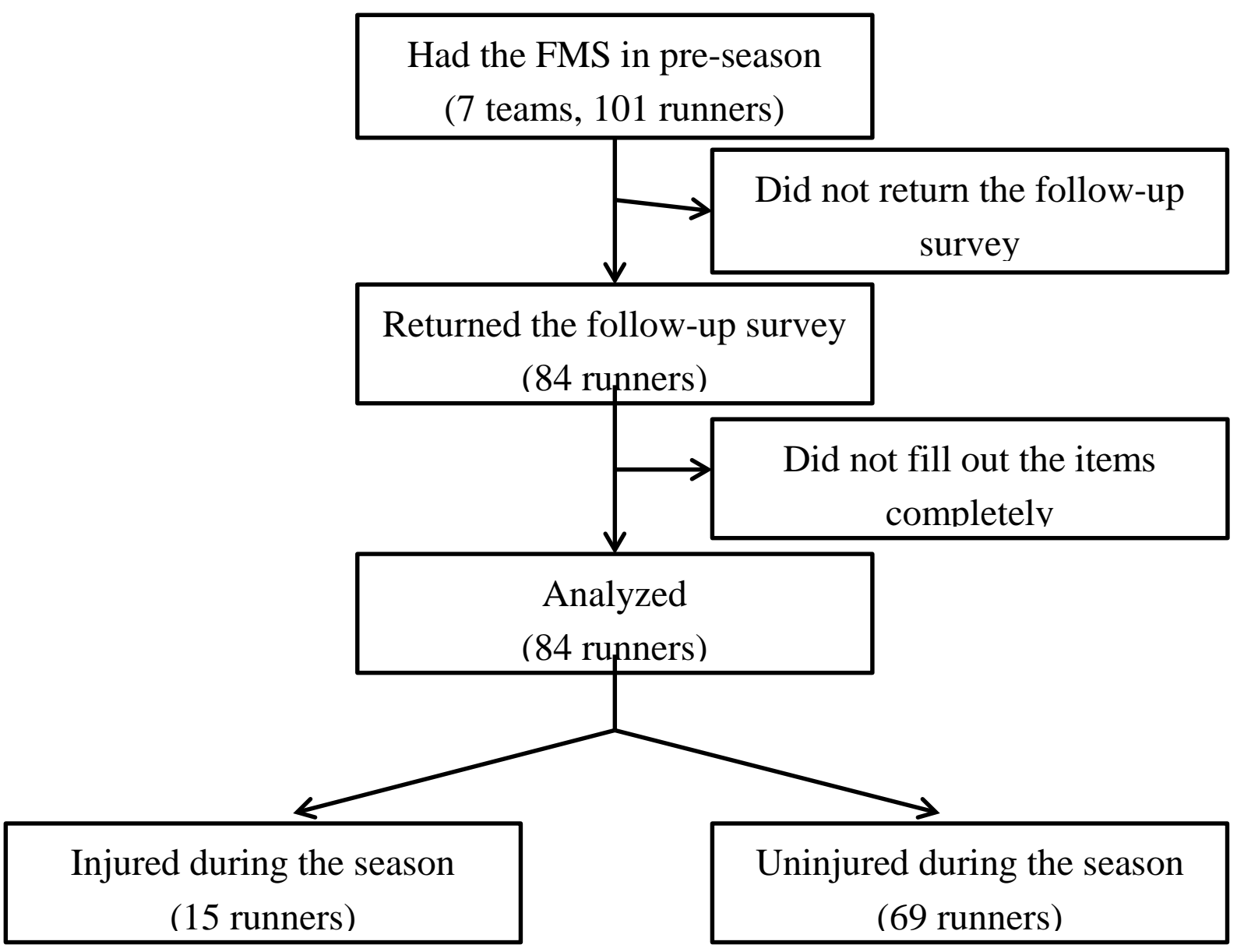

2 FIGURE 1. Flow chart illustrating the process of the study. 


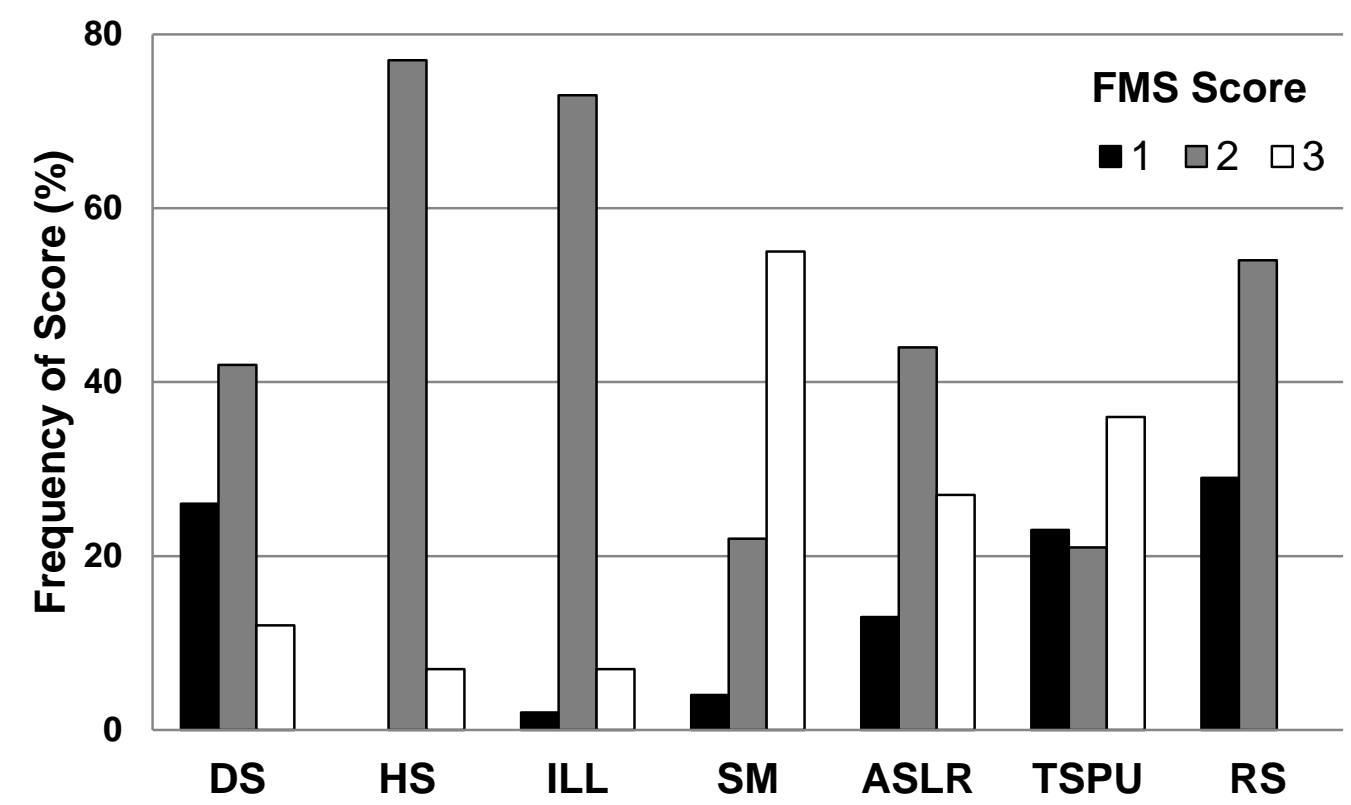

2 FIGURE 2. Distribution of scores for each functional movement screen (FMS) component

3 test. DS = deep squat, HS = hurdle step, ILL = in-line lunge, SM = shoulder mobility, ASLR 4 = active straight leg raise, TSPU = trunk stability push-up, RS = rotary stability. 


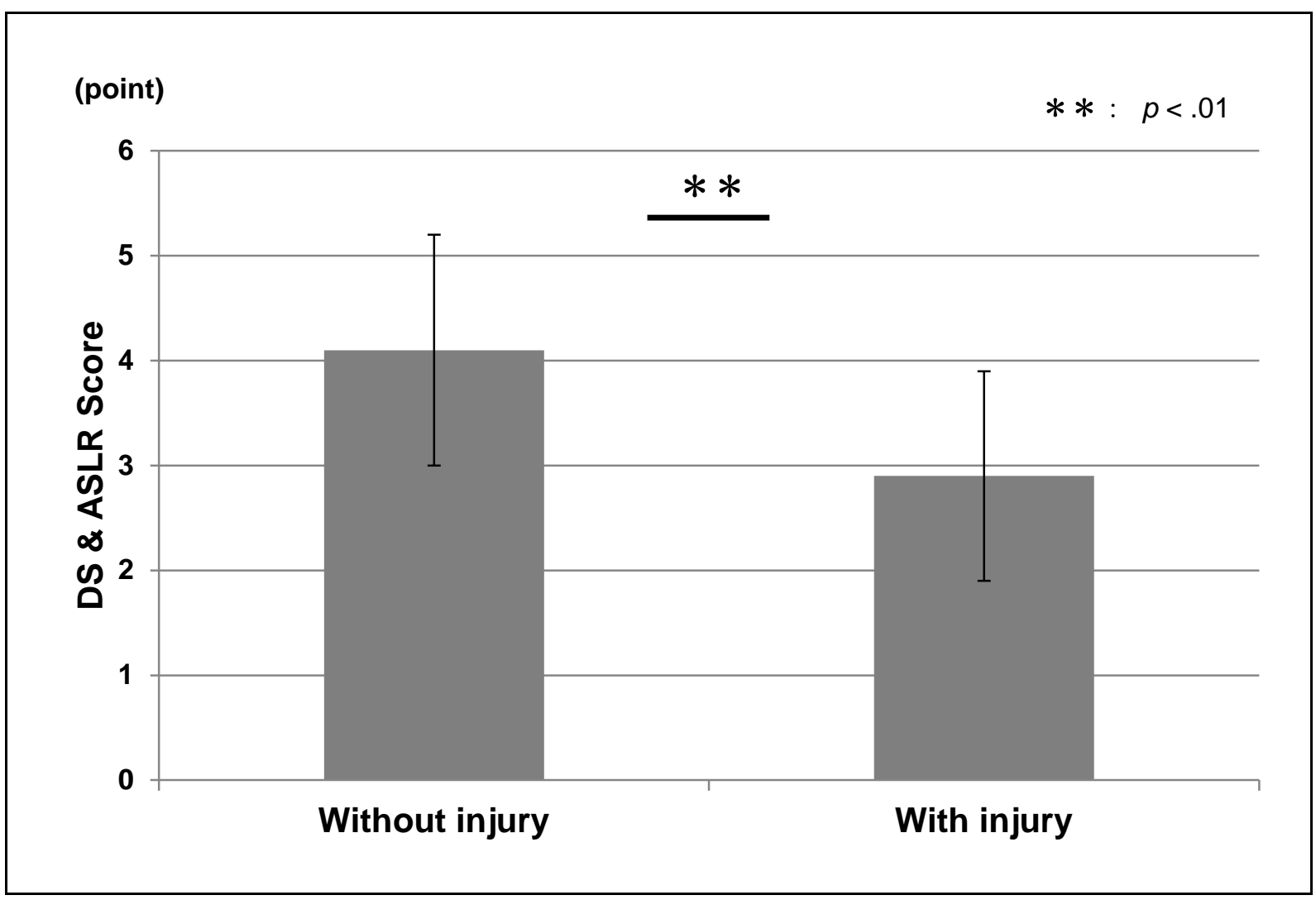

FIGURE 3. Comparison of DS \& ASLR scores between groups with and without running

3 injuries. 


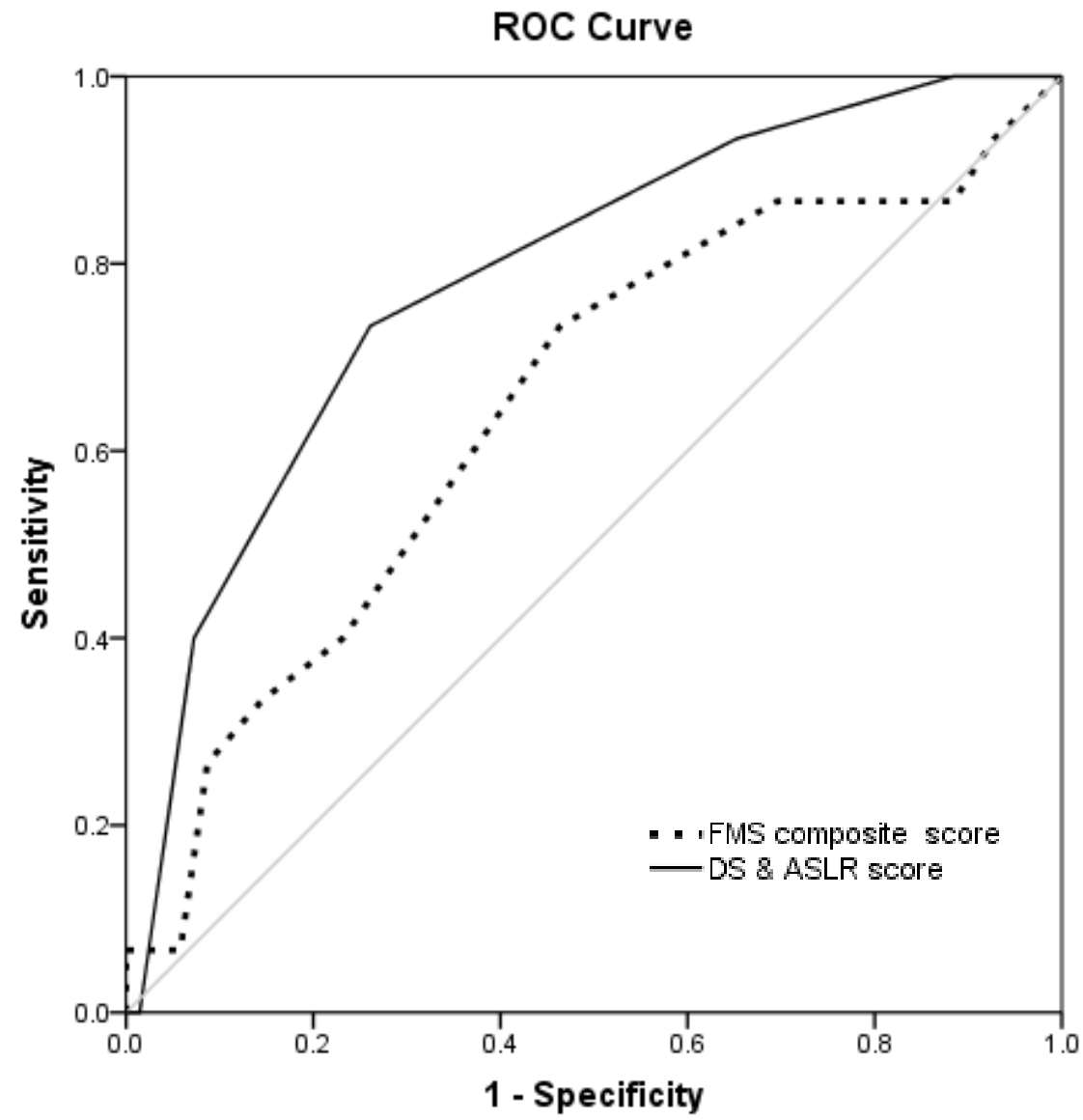

1

2 FIGURE 4. Receiver-operator characteristic (ROC) curves for FMS composite and DS \&

3 ASLR score. 
1 TABLE 1. Interrater reliability for the FMS composite score.

\begin{tabular}{|c|c|c|c|c|c|c|c|c|c|}
\hline \multirow{3}{*}{$\begin{array}{l}\text { ICC } \\
(2,1)\end{array}$} & \multirow{3}{*}{$\begin{array}{c}95 \% \mathrm{C} \\
\mathrm{I}\end{array}$} & \multicolumn{5}{|c|}{ Bland-Altman plot } & \multirow{3}{*}{$\begin{array}{l}\text { SE } \\
\mathrm{M}\end{array}$} & \multirow{3}{*}{$\begin{array}{l}\text { MD } \\
\mathrm{C}_{95}\end{array}$} & \multirow{3}{*}{$\begin{array}{c}\text { SE } \\
\mathrm{P}\end{array}$} \\
\hline & & \multicolumn{2}{|c|}{ fixed bias } & \multicolumn{3}{|c|}{ proportional bias } & & & \\
\hline & & $95 \% \mathrm{CI}$ & $\begin{array}{c}\text { presence/ab } \\
\text { sence }\end{array}$ & $\begin{array}{l}\text { test } \\
\text { corr }\end{array}$ & $\begin{array}{l}\text { no } \\
\text { tion }\end{array}$ & $\begin{array}{c}\text { presence/ab } \\
\text { sence }\end{array}$ & & & \\
\hline \multirow{2}{*}{0.98} & $0.93-1$ & $-0.83-0$ & \multirow{2}{*}{ absence } & $\mathrm{r}=$ & $\mathrm{p}=$ & \multirow{2}{*}{ absence } & 0.3 & \multirow{2}{*}{0.87} & 0.4 \\
\hline & .00 & .43 & & -0.44 & 0.90 & & 1 & & 4 \\
\hline
\end{tabular}

95\%CI: 95\% confidence interval, SEM = standard error of measurement, MDC = minimum

difference to be considered real, SEP = standard error of prediction 
TABLE 2. Interrater reliability for each FMS component test.

\begin{tabular}{lcc}
\hline \multicolumn{1}{c}{ Test } & Kappa & Strength of agreement \\
\hline Deep squat & 1.000 & Excellent \\
Hurdle step & 1.000 & Excellent \\
In-line lunge & 1.000 & Excellent \\
Shoulder mobility & 1.000 & Excellent \\
Active straight leg raise & 0.831 & Substantial \\
Trunk stability push-up & 0.836 & Substantial \\
Rotary stability & 1.000 & Excellent \\
\hline
\end{tabular}


1 TABLE 3. Comparison of runners with and without running injuries during the season.

\begin{tabular}{|c|c|c|c|}
\hline \multirow{2}{*}{ Variable } & \multicolumn{2}{|c|}{ Serious running injury } & \multirow{2}{*}{$P$ value } \\
\hline & without $(\mathrm{n}=69)$ & with $(\mathrm{n}=15)$ & \\
\hline \multicolumn{4}{|l|}{ Characteristics } \\
\hline Age $(\text { year })^{\dagger}$ & $20.1 \pm 1.2$ & $19.6 \pm 0.9$ & 0.15 \\
\hline Height (cm) & $171.3 \pm 4.3$ & $172.7 \pm 5.6$ & 0.29 \\
\hline Weight (kg) & $57.3 \pm 4.2$ & $58.4 \pm 5.0$ & 0.39 \\
\hline Running experience (year) ${ }^{\dagger}$ & $6.9 \pm 2.2$ & $6.7 \pm 2.4$ & 0.64 \\
\hline Weekly training sessions (day/week) ${ }^{\dagger \dagger}$ & $5.9 \pm 0.6$ & $5.9 \pm 0.6$ & 0.85 \\
\hline Weekly mileage $(\mathrm{km} / \text { week })^{\dagger}$ & $80.9 \pm 53.8$ & $98.4 \pm 57.3$ & 0.26 \\
\hline Performance (\%) & $87.6 \pm 4.1$ & $88.7 \pm 3.6$ & 0.34 \\
\hline Injury history, $(\mathrm{n}, \%)^{\dagger+\dagger}$ & $34(49.3 \%)$ & $8(53.3 \%)$ & 1.00 \\
\hline \multicolumn{4}{|l|}{ FMS } \\
\hline FMS total score ${ }^{\dagger}$ & $14.4 \pm 2.2$ & $13.3 \pm 2.7$ & 0.10 \\
\hline Deep squat $^{\dagger \dagger}$ & $1.8 \pm 0.7$ & $1.3 \pm 0.7$ & $0.01 *$ \\
\hline Hurdles step ${ }^{\dagger \dagger}$ & $2.1 \pm 0.3$ & $2.0 \pm 0.0$ & 0.20 \\
\hline In-line lunge $e^{\dagger \dagger}$ & $2.0 \pm 0.4$ & $1.9 \pm 0.7$ & 0.26 \\
\hline Shoulder mobility ${ }^{\dagger \dagger}$ & $2.6 \pm 0.8$ & $2.5 \pm 0.6$ & 0.36 \\
\hline Active straight leg raise ${ }^{\dagger \dagger}$ & $2.3 \pm 0.6$ & $1.6 \pm 0.5$ & $<0.01^{* *}$ \\
\hline Trunk stability push-up ${ }^{\dagger \dagger}$ & $2.0 \pm 1.0$ & $2.5 \pm 0.8$ & 0.06 \\
\hline Rotary stability $^{\dagger \dagger}$ & $1.6 \pm 0.5$ & $1.6 \pm 0.6$ & 0.97 \\
\hline
\end{tabular}

${ }^{\dagger}$ Continuous data are expressed as the mean \pm SD (tested by the student's t-tests).

${ }^{\dagger \dagger}$ Non parametric data are expressed as the mean \pm SD (tested by the Mann-Whitney U tests).

${ }^{\dagger+\dagger}$ Categorical data are expressed as numbers (percentages) (tested by the chi-squared test). 
1 TABLE $4.2 \times 2$ contingency table: FMS composite score $\times$ running injuries.

\begin{tabular}{|l|c|c|}
\hline \multirow{2}{*}{} & \multicolumn{2}{|c|}{ Running injuries } \\
\cline { 2 - 3 } & without & with \\
\hline FMS composite score $\leq 14$ & 32 & 11 \\
\hline FMS composite score $\geq 15$ & 37 & 4 \\
\hline
\end{tabular}

2 
1 TABLE $5.2 \times 2$ contingency table: DS \& ASLR score $\times$ running injuries.

\begin{tabular}{|l|c|c|}
\hline \multirow{2}{*}{} & \multicolumn{2}{|c|}{ Running injuries } \\
\cline { 2 - 3 } & without & with \\
\hline DS \& ASLR score $\leq 3$ & 18 & 11 \\
\hline DS \& ASLR score $\geq 4$ & 51 & 4 \\
\hline
\end{tabular}


1 TABLE 6. Influence of the FMS on running injury.

\begin{tabular}{lcccccc}
\hline & \multicolumn{3}{c}{ univariate } & \multicolumn{3}{c}{ multivariate* } \\
& OR & $95 \%$ CI & $P$ value & OR & $95 \%$ CI & $P$ value \\
\hline FMS composite score $\leq 14$ & 3.2 & $0.9-11.0$ & 0.07 & 3.0 & $0.8-11.6$ & 0.10 \\
\hline DS \& ASLR score $\leq 3$ & 7.8 & $2.2-27.6$ & $<0.01^{* *}$ & 9.7 & $2.1-44.4$ & $<0.01^{* *}$ \\
\hline
\end{tabular}

*Adjusted for age, height, weight, running experience, weekly training sessions, weekly mileage, performance, and injury history. 